\title{
Discrete-trial probability learning in rats: Effects of local contingencies of reinforcement
}

\author{
KYOICHI HIRAOKA \\ Hirosaki University, Hirosaki, Japan
}

\begin{abstract}
Three groups of rats were trained using a noncorrection procedure on a probability learning task in which responses on one lever produced reinforcement on $61 \%$ of the trials and responses on the other lever produced reinforcement on the remaining trials. For Group RAN, there were no sequential constraints, but for Groups REP and ALT, the lever on which reinforcement was produced on a given trial depended upon the lever that had been designated correct on the previous trial. For Group REP, the locus of reinforcement was repeated on approximately $80 \%$ of trials; Group ALT was required to switch to the other lever on approximately $80 \%$ of trials. The maximizing strategy for Group RAN was exclusive responding to the majority lever, for Group ALT, it was "win-shift, lose-stay," and for Group REP, "win-stay, lose-shift." Subjects from both the REP and ALT groups tended to maximize momentarily, thereby showing a lower relative frequency of majority responses than did subjects from the RAN group. The differences between groups cannot be accounted for by a molar analysis; a molecular analysis is needed.
\end{abstract}

Choice behavior in animals has recently been studied intensively in the field of operant conditioning (for a review, see de Villiers, 1977). A frequent outcome of choice experiments is the phenomenon of matching, that is, the occurrence of relative response rates approximating relative reinforcement ratios. This phenomenon, especially common on concurrent variable-interval variableinterval (VI-VI) schedules, has been explained differently by "'molar" and "molecular" analyses. Herrnstein (1970), a molar analyst, holds that the overall matching relation in itself is a fundamental process which may reflect relative response strength. Shimp $(1966,1975)$ argues for a molecular analysis in which matching is seen as a consequence of "momentary maximizing," that is, choosing the alternative with the higher momentary probability of reinforcement.

Many authors (Herrnstein, 1970; Mackintosh, 1974; Shimp, 1975; Staddon, Hinson, \& Kram, 1981) have noted the similarity of discrete-trial probability learning experiments to concurrent free-operant schedules. Discrete-trial experiments on probability learning may thus prove useful in assessing the molecular-level analysis of choice behavior, since local contingencies of reinforcement can be determined exactly in these experiments. For example, probability learning experiments with known molecular contingencies of reinforcement (e.g., Hale \& Shimp, 1975; Shimp, 1966, 1976; Williams, 1972) have shown that pigeons respond optimally (i.e., momentarily maximize) according to the local structures of reinforcement probability.

The author wishes to thank Geoffrey Hall at the University of York for his helpful comments on an earlier draft of this paper. Requests for reprints should be sent to Kyoichi Hiraoka, Department of Psychology, Hirosaki University, Hirosaki, 036 Japan.
The present study aimed to shed further light on molecular choice behavior by investigating the effects of local contingencies of reinforcement on probability learning in rats. The present experiment had three major procedural features, which had not been employed together before. (1) The use of rats, rather than pigeons, as subjects should validate the comparison between the results of the present study and those of previous experiments using rats (Sutherland \& Mackintosh, 1971). (2) A noncorrection, rather than a correction, procedure was used. The question of correction versus noncorrection procedure has been known to be an important variable in probability-learning experiments: a noncorrection procedure produces much higher responding to the more frequently reinforced alternative than does a correction procedure (Sutherland $\&$ Mackintosh, 1971; Uhl, 1963). The majority of discretetrial experiments reporting optimal responding have employed the correction procedure. Therefore, it has not been clear whether animals respond optimally without correction. Another reason for using a noncorrection procedure is that the correction procedure complicates the analysis of actual reinforcement probabilities (Herrnstein, 1970). (3) In contrast to the studies cited above, overall probabilities on two levers were not equal but were apportioned at approximately .60 and .40 , thus making the present experiment more similar to the traditional probability learning procedure. Then, sequential dependencies of assigning reinforcement were manipulated (cf. Shimp, 1976; Williams, 1972). For one group (RAN), the schedule was a random one. For a second group (ALT), "winshift, lose-stay" behavior was reinforced approximately $80 \%$ of the time. For a third group (REP), the schedule was "win-stay, lose-shift." Optimal strategies are exclusive responding to the majority lever for the first group, and consistent win-shift, lose-stay and win-stay, lose-shift 
responses for the second and third groups, respectively. If rats ignore the molecular contingencies, all groups should respond nearly always to the majority lever. To the extent that they respond optimally to the local contingencies, the ALT and REP groups should respond more to the minority lever than should the RAN group.

\section{METHOD}

\section{Subjects}

Twenty-seven experimentally naive male albino rats of the Wistar strain were used as subjects. They were approximately 120 days old at the start of the experiment. All animals were maintained at approximately $80 \%$ of their free-feeding weights. Water was continuously available in their home cages.

\begin{abstract}
Apparatus
A two-lever rat chamber $(35 \times 30 \times 31 \mathrm{~cm}$ high) was used, the inside of which was painted a uniform gray. One wall was made of $.1-\mathrm{cm}$ aluminum and the others of $1.5-\mathrm{cm}$ plywood. The chamber was covered with .5-cm acrylic glass on top. In the aluminum wall, two steel retractable levers and a food cup were mounted. Each lever was $1.5 \times 3.2 \mathrm{~cm}$ and protruded $1.5 \mathrm{~cm}$ into the box. The levers were mounted $8 \mathrm{~cm}$ above the wire-mesh floor and were $18 \mathrm{~cm}$ apart center to center. An approximately 15 -g force was required to depress a lever and to operate a microswitch effectively. A plastic food cup $(2.9 \times 2.5 \times 2.1 \mathrm{~cm}$ deep) was located midway between the levers and $3 \mathrm{~cm}$ above the floor. Food reinforcement consisted of a single pellet of approximately $35 \mathrm{mg}$. A $10-W$ lamp $(100 \mathrm{~V} \mathrm{ac})$ mounted on the wall opposite to the aluminum one illuminated the interior of the box.

All experimenter-controlled events, for example, the intertrial interval (ITI), except for the sequence of alternatives with reinforcement, which was manually operated by a switch, were operated by automatic controlling devices.
\end{abstract}

\section{Procedure}

After leverpress training, a 30-trial session to determine position preference was run in which both levers were inserted with a 10-sec ITI and a response to either lever was always reinforced. During the ITI, both levers were retracted. Before entering into probability training, the subjects were divided into three groups of nine rats each. An effort was made to equalize the groups in means and standard deviations of the number of responses to the right lever during the preference test session. In probability training, all rats were given 42 daily 31 -trial sessions, that is, a total of 1,302 trials, on a spatial 61:39 problem with a noncorrection procedure. Reinforcement was assigned on each trial according to the sequences shown in Table 1. One of the four 31-trial sequences was used each day according to a random order. The majority lever was the right lever for four subjects and the left for the remaining animals in each group. The three groups differed in local contingencies of reinforcement. Averaging across the four sequences, the numbers of reinforcements assigned on the lever opposite to the one that was correct on the immediately preceding trial, that is, RL + LR in Table 1, were $15.00(50.0 \%), 23.75(79.2 \%)$, and $5.75(19.2 \%)$ for Groups RAN, ALT, and REP, respectively. The mean numbers of cases in which reinforcement was assigned on the same lever as on the previous trials, that is, $R R+L L$, were $15.00(50.0 \%), 6.25$ $(20.8 \%)$, and $24.25(80.8 \%)$. Thus, if the subjects consistently followed a win-stay, lose-shift strategy from the second trial of each session, their behavior would be reinforced $50.0 \%, 20.8 \%$, and $80.8 \%$ of the time for Groups RAN, ALT, and REP, respectively. Win-shift, lose-stay behavior, on the other hand, would be reinforced $50.0 \%, 79.2 \%$, and $19.2 \%$ of the time.

At the start of a trial, both levers were inserted and the houselight was turned on. A correct response was immediately followed by the delivery of a pellet; an incorrect response had no consequence. Both levers were retracted and the houselight went off for a 15 -sec ITI approximately .5 sec after the depression of either lever whether the response produced a food pellet or not.

\section{RESULTS}

\section{Overall Choice}

Figure 1 shows the relative frequency of responses to the majority lever for the three groups. Majority responses of the rats in Group RAN increased monotonically, and

Table 1

Arrangement of Reinforcement

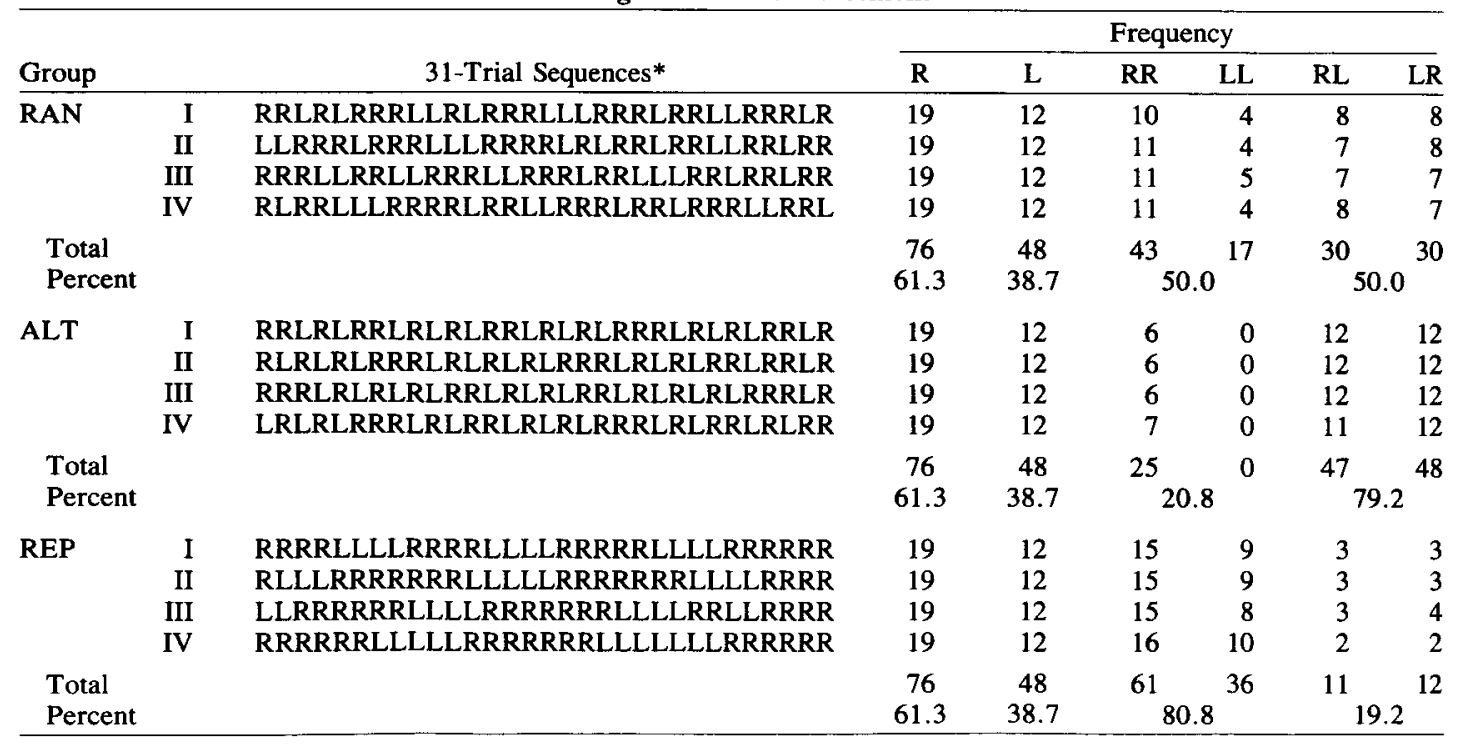

*In the case of the right lever being the majority lever. With the left as the majority, $R$ and $L$ were reversed. 


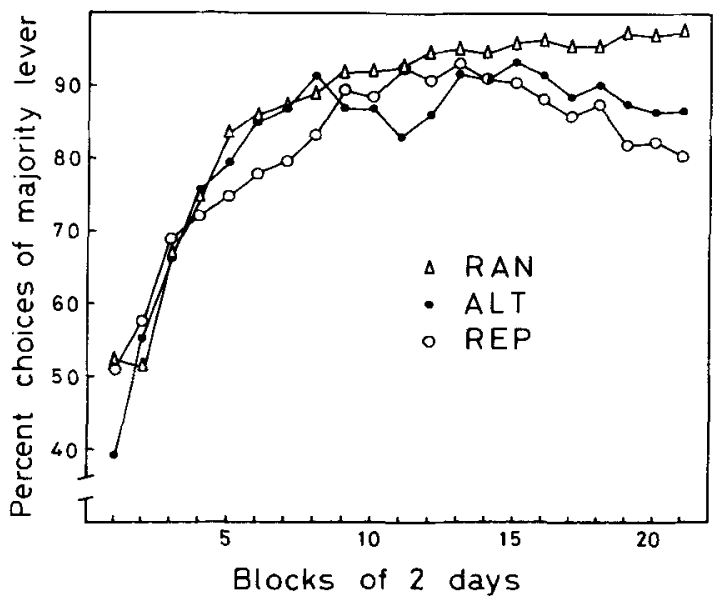

Figure 1. Mean relative frequency of responses to the majority lever for the three groups. these rats were responding almost exclusively to that lever by the end of training. This pattern of responding is typical of that previously reported in probability learning experiments with noncorrection procedures (Sutherland \& Mackintosh, 1971). The curves for the other two groups went up in the same way as that of Group RAN until midway through training. Then, however, both curves declined. The decline is shown somewhat more clearly for Group REP, which eventually performed at approximately the $80 \%$ level. An analysis of variance carried out on the number of responses to the majority lever revealed a significant effect of blocks (of two sessions) $[\mathrm{F}(20,480)$ $=41.74, \mathrm{p}<.01]$ and a significant interaction between groups and blocks $[\mathrm{F}(40,480)=2.57, \mathrm{p}<.01]$. An additional one-way analysis of variance was conducted on performance averaged within each seven-block segment. The effect of groups was significant in Blocks 15-21 $[\mathrm{F}(2,24)=10.61, \mathrm{p}<.01]$, but not in Blocks $1-7$

Table 2

Relative Frequency of Majority Responses and the Number of Reinforcers Obtained During the Last Six Sessions

\begin{tabular}{|c|c|c|c|c|c|}
\hline \multirow[b]{2}{*}{ Group } & \multirow[b]{2}{*}{ Rat } & \multirow{2}{*}{$\begin{array}{c}\text { Majority } \\
\text { Responses }\end{array}$} & \multicolumn{3}{|c|}{ Reinforcers } \\
\hline & & & Observed & Random* & Optimal** \\
\hline RAN & $\begin{array}{r}1 \\
6 \\
7 \\
11 \\
15 \\
17 \\
19 \\
23 \\
26\end{array}$ & $\begin{array}{r}.973 \\
.989 \\
.989 \\
.892 \\
.962 \\
1.000 \\
.962 \\
1.000 \\
1.000\end{array}$ & $\begin{array}{l}113 \\
112 \\
114 \\
104 \\
109 \\
114 \\
113 \\
114 \\
114\end{array}$ & $\begin{array}{l}112.9 \\
113.6 \\
113.6 \\
109.5 \\
112.4 \\
114.0 \\
112.4 \\
114.0 \\
114.0\end{array}$ & \\
\hline Average & & .974 & 111.9 & 112.9 & \\
\hline ALT & $\begin{array}{r}2 \\
4 \\
9 \\
10 \\
13 \\
16 \\
21 \\
24 \\
25\end{array}$ & $\begin{array}{l}1.000 \\
.780 \\
.903 \\
.946 \\
.823 \\
.828 \\
.801 \\
.914 \\
.855\end{array}$ & $\begin{array}{l}114 \\
114 \\
119 \\
114 \\
119 \\
106 \\
113 \\
114 \\
106\end{array}$ & $\begin{array}{l}114.0 \\
104.8 \\
110.0 \\
111.8 \\
106.6 \\
106.8 \\
105.7 \\
110.4 \\
107.9\end{array}$ & $\begin{array}{l}114.0 \\
126.1 \\
119.3 \\
117.0 \\
123.8 \\
120.9 \\
125.0 \\
118.7 \\
120.7\end{array}$ \\
\hline Average & & .872 & 113.2 & 108.7 & 120.6 \\
\hline REP & $\begin{array}{r}3 \\
5 \\
8 \\
12 \\
14 \\
18 \\
20 \\
22 \\
27\end{array}$ & $\begin{array}{l}.871 \\
.839 \\
.720 \\
.887 \\
.763 \\
.769 \\
.780 \\
.780 \\
.930\end{array}$ & $\begin{array}{l}118 \\
118 \\
120 \\
125 \\
118 \\
121 \\
112 \\
115 \\
117\end{array}$ & $\begin{array}{l}108.6 \\
107.2 \\
102.7 \\
109.3 \\
104.1 \\
104.3 \\
104.8 \\
104.8 \\
111.1\end{array}$ & $\begin{array}{l}126.7 \\
129.8 \\
139.9 \\
125.1 \\
137.2 \\
136.7 \\
135.6 \\
135.6 \\
119.3\end{array}$ \\
\hline Average & & .815 & 118.2 & 106.3 & 131.8 \\
\hline
\end{tabular}

*Expected on the basis of a random response pattern. The scores are calculated by $.613 \cdot A_{1}+.387 \cdot A_{2}$, where $A_{1}$ and $A_{2}$ represent the frequencies of majority and minority responses, respectively. $\quad{ }^{* *}$ Expected on the basis of optimal response strategies. The scores are calculated by $.648 \cdot A_{2}+110-.352 \cdot A_{2}+R_{1}$, for Group ALT and $.764 \cdot A_{2}+109-.236 \bullet A_{2}+R_{1}$ for Group REP, where $A_{2}$ and $R_{1}$ represent the frequency of minority responses from the second trial of sessions, and the amount of reinforcers actually obtained on the first trial, respectively. The rationale for calculation is as follows: Suppose that responses to the minority lever from the second trial of each session are all optimal (win-shift, lose-stay and win-stay, lose-shift for Groups ALT and REP, respectively). Then these minority responses will be reinforced .648 and.764 of the time for Groups ALT and REP, respectively. On the majority lever, rats will earn all the reinforcers arranged on this lever minus the number of unreinforced responses to the minority lever. Actual amount of reinforcers were applied for the first trials. 
$[F(2,24)=.46]$ or Blocks $8-14[F(2,24)=.89]$, thereby confirming the reliability of the divergence of groups seen at the end of training.

Table 2 compares the relative frequency of responses to the majority lever and the pooled number of reinforcers on both levers over the last six sessions (three blocks) when performance was stable. As might be expected from the data shown in Figure 1, the relative frequency of majority responses was highest for Group RAN, intermediate for Group ALT, and lowest for Group REP. The order of groups was reversed for the amount of reinforcers gained: Group REP was the highest, then came Group ALT, and finally Group RAN, the lowest. This difference among groups was significant $[\mathrm{F}(2,24)=6.47$, $\mathrm{p}<.01]$. In order to examine the relationships between within-group variations in frequency of majority responses and reinforcers gained, a correlation coefficient was calculated between these two scores for each group. Group RAN showed a strong positive relation, with $\mathrm{r}=.932$ $[\mathrm{t}(7)=6.80, \mathrm{p}<.01]$, suggesting that the more the subjects make majority responses, the more food they get. Groups ALT and REP, on the other hand, had much lower coefficients, with $r=.173[t(7)=.46]$ and $r=.184$ $[t(7)=.50]$, respectively. The observed amount of reinforcement was compared with the value expected by chance ("Random" in Table 2). Subjects in Groups ALT and REP gained more reinforcers than their corresponding chance values $[\mathrm{t}(8)=2.71, \mathrm{p}<.05$ and $\mathrm{t}(8)=8.50$, $\mathrm{p}<.01$, respectively], whereas Group RAN did not $[\mathrm{t}(8)$ $=1.39$ ]. These deviations from chance values for Groups ALT and REP were in the direction toward the scores expected on the basis of optimal strategies ("Optimal" in Table 2).

These results suggest that rats in Groups ALT and REP increased the amount of food per session, by increasing their responses to the minority lever, and that their choice behavior was not random. In Group RAN, on the other hand, it seems that increasing minority responses decreased the amount of reinforcement.

\section{Local Structures of Responding}

The rats' responses immediately following different outcomes were analyzed, and the number of majority and minority responses in the case of reinforcement or nonreinforcement on the immediately preceding trial is shown in Table 3a. The outcome of the preceding trial did not affect the distribution of responses in Group RAN, but did do so in Groups ALT and REP. When a response was reinforced on a given trial, the percentage of majority responses on the next trial was significantly lower than expected for Group ALT, but significantly higher than expected for Group REP. The expected score in each case was in proportion to the distribution of majority and minority responses regardless of preceding outcomes. When a response was not reinforced, on the other hand, percent majority responses on the next trial were significantly higher for Group ALT and significantly lower for
Group REP than their corresponding expected values. The directions of divergence from expected values following different outcomes were unchanged whether the preceding response was to the majority or to the minority lever. That is to say, following a majority response, win-shift, lose-stay responses for Group ALT and win-stay, loseshift responses for Group REP were more frequent than expected, whereas following a minority response, so were win-stay, lose-shift responses and win-shift, lose-stay responses for Groups ALT and REP, respectively.

Table $3 \mathrm{~b}$ shows the number of reinforcements actually obtained immediately following different outcomes. If there is some correspondence between distributions of responses and reinforcers in each outcome condition, a matching relation may be considered as supported. Comparing Table $3 a$ with Table $3 b$, however, it cannot be concluded that the distributions of responses closely parallel those of the reinforcements. For Group REP, for example, following an unreinforced majority response, the animals made more responses on the majority lever than on the minority one, although they earned more reinforcers on the minority lever than on the majority one. Furthermore, the percentage of reinforcements on the majority lever following a reinforced minority response was higher than that following nonreinforcement on that lever for Group ALT, although lower for Group REP. As for the percentages of majority responses, on the other hand, these relations were completely reversed.

\section{DISCUSSION}

The results of the overall choice measure in this experiment indicate that rats trained on a random schedule responded almost exclusively to the majority lever, whereas those trained with sequential probabilities differing from .50 tended to depart from a pattern of exclusive responding to the majority lever. The optimal response pattern for Group RAN in this experiment was to respond exclusively to the majority lever, since the reinforcement schedule for this group had no particular local structures. It may thus be said that subjects in this group maximized. Previous probability learning experiments using noncorrection procedures have reported that the responses of their subjects were absorbed to the majority alternative even with such a relatively small difference of reinforcement probability as .60:.40 (Lehr \& Pavlik, 1970; Meyer, 1960; Poland \& Warren, 1967). But absorption to the majority alternative is not the only possible outcome for probability learning under noncorrection, as the results for Groups ALT and REP in the present experiment show.

The analysis of the local structure of responding showed that subjects in Groups ALT and REP responded systematically on the basis of the sequential dependencies of reinforcement, whereas those in Group RAN, with no sequential dependencies, behaved randomly. The optimal strategies for Groups ALT and REP were consistent winshift, lose-stay and win-stay, lose-shift, respectively, and 
Table 3a

Distribution of Responses Immediately Following Different Outcomes During the Last Six Sessions

\begin{tabular}{|c|c|c|c|c|c|c|c|c|c|}
\hline \multirow[b]{2}{*}{ Group } & \multirow[b]{2}{*}{ Rat } & \multicolumn{2}{|c|}{$\begin{array}{c}\text { Following } A_{1} \\
\text { Reinforced }\end{array}$} & \multicolumn{2}{|c|}{$\begin{array}{l}\text { Following } A_{1} \\
\text { Unreinforced }\end{array}$} & \multicolumn{2}{|c|}{$\begin{array}{c}\text { Following } \mathrm{A}_{2} \\
\text { Reinforced } \\
\end{array}$} & \multicolumn{2}{|c|}{$\begin{array}{l}\text { Following } \mathbf{A}_{2} \\
\text { Unreinforced }\end{array}$} \\
\hline & & $\mathrm{A}_{1}$ & $\mathbf{A}_{2}$ & $\mathrm{~A}_{1}$ & $\mathrm{~A}_{2}$ & $A_{1}$ & $\mathbf{A}_{2}$ & $A_{1}$ & $\mathrm{~A}_{2}$ \\
\hline$\overline{R A N}$ & $\begin{array}{r}1 \\
6 \\
7 \\
11 \\
15 \\
17 \\
19 \\
23 \\
26\end{array}$ & $\begin{array}{r}106 \\
107 \\
107 \\
89 \\
98 \\
110 \\
101 \\
110 \\
110\end{array}$ & $\begin{array}{l}1 \\
1 \\
2 \\
6 \\
6 \\
0 \\
5 \\
0 \\
0\end{array}$ & $\begin{array}{l}67 \\
69 \\
69 \\
53 \\
70 \\
70 \\
65 \\
70 \\
70\end{array}$ & $\begin{array}{r}1 \\
1 \\
0 \\
12 \\
0 \\
0 \\
2 \\
0 \\
0\end{array}$ & $\begin{array}{l}2 \\
0 \\
1 \\
5 \\
0 \\
0 \\
3 \\
0 \\
0\end{array}$ & $\begin{array}{l}0 \\
0 \\
0 \\
0 \\
0 \\
0 \\
0 \\
0 \\
0\end{array}$ & $\begin{array}{r}3 \\
2 \\
1 \\
13 \\
6 \\
0 \\
4 \\
0 \\
0\end{array}$ & $\begin{array}{l}0 \\
0 \\
0 \\
2 \\
0 \\
0 \\
0 \\
0 \\
0\end{array}$ \\
\hline $\begin{array}{l}\text { Total } \\
\mathrm{A}_{1} \text { Percent } \\
\chi^{2}\end{array}$ & & \multicolumn{2}{|c|}{$\begin{array}{r}97.8 \\
.627\end{array}$} & \multicolumn{2}{|c|}{$\begin{array}{r}97.4 \\
.001\end{array}$} & \multicolumn{2}{|c|}{$\begin{array}{c}100.0 \\
.137\end{array}$} & \multicolumn{2}{|c|}{$\begin{array}{r}93.5 \\
.629\end{array}$} \\
\hline $\mathrm{ALT}$ & $\begin{array}{r}2 \\
4 \\
9 \\
10 \\
13 \\
16 \\
21 \\
24 \\
26\end{array}$ & $\begin{array}{r}108 \\
59 \\
89 \\
94 \\
67 \\
72 \\
65 \\
91 \\
74\end{array}$ & $\begin{array}{r}0 \\
30 \\
13 \\
8 \\
27 \\
16 \\
25 \\
10 \\
16\end{array}$ & $\begin{array}{l}72 \\
48 \\
59 \\
66 \\
52 \\
50 \\
48 \\
59 \\
56\end{array}$ & $\begin{array}{r}0 \\
7 \\
2 \\
2 \\
1 \\
10 \\
6 \\
5 \\
7\end{array}$ & $\begin{array}{r}0 \\
13 \\
8 \\
5 \\
15 \\
10 \\
14 \\
8 \\
8\end{array}$ & $\begin{array}{l}0 \\
8 \\
3 \\
0 \\
4 \\
2 \\
4 \\
0 \\
2\end{array}$ & $\begin{array}{r}0 \\
15 \\
6 \\
5 \\
13 \\
18 \\
16 \\
6 \\
16\end{array}$ & $\begin{array}{l}0 \\
0 \\
0 \\
0 \\
1 \\
2 \\
2 \\
1 \\
1\end{array}$ \\
\hline $\begin{array}{l}\text { Total } \\
A_{1} \text { Percent } \\
\chi^{2}\end{array}$ & & \multicolumn{2}{|c|}{$\begin{array}{c}83.2 \\
12.270^{* *}\end{array}$} & \multicolumn{2}{|c|}{$\begin{array}{c}92.7 \\
15.054^{* *}\end{array}$} & \multicolumn{2}{|c|}{$\begin{array}{c}77.9 \\
8.112^{* *}\end{array}$} & \multicolumn{2}{|c|}{$\begin{array}{c}93.1 \\
3.259 *\end{array}$} \\
\hline REP & $\begin{array}{r}3 \\
5 \\
8 \\
12 \\
14 \\
18 \\
20 \\
22 \\
27\end{array}$ & $\begin{array}{r}94 \\
88 \\
76 \\
100 \\
81 \\
83 \\
80 \\
76 \\
101\end{array}$ & $\begin{array}{r}3 \\
8 \\
10 \\
3 \\
8 \\
8 \\
7 \\
13 \\
2\end{array}$ & $\begin{array}{l}39 \\
36 \\
14 \\
40 \\
17 \\
23 \\
28 \\
31 \\
54\end{array}$ & $\begin{array}{l}19 \\
19 \\
29 \\
16 \\
31 \\
24 \\
25 \\
20 \\
10\end{array}$ & $\begin{array}{r}15 \\
16 \\
26 \\
15 \\
23 \\
21 \\
17 \\
20 \\
8\end{array}$ & $\begin{array}{l}0 \\
1 \\
3 \\
1 \\
1 \\
4 \\
2 \\
1 \\
0\end{array}$ & $\begin{array}{r}9 \\
9 \\
13 \\
4 \\
15 \\
10 \\
15 \\
12 \\
5\end{array}$ & $\begin{array}{l}1 \\
3 \\
9 \\
1 \\
4 \\
7 \\
6 \\
7 \\
0\end{array}$ \\
\hline $\begin{array}{l}\text { Total } \\
A_{1} \text { Percent } \\
\chi^{2}\end{array}$ & & & 62 & 282 & 193 & $\begin{array}{r}161 \\
1\end{array}$ & 13 & 92 & 38 \\
\hline
\end{tabular}

Note $-A_{1}=$ the response to the majority lever; $A_{2}=$ the response to the minority lever; Expected frequencies for chi-square tests were proportional to the distributions of $A_{1}$ and $A_{2}$ regardless of preceding outcomes (see Table 2). $d f=1 . \quad * 05<p<.10 . \quad * * p<.01$

on the whole the behavior of the animals in these groups accorded with these strategies. Although the animals did not shift on every appropriate occasion, it is clear that the bulk of shifts to the minority lever took place when these were more likely to be reinforced than when they were not. Shimp $(1966,1969)$ proposed a "momentary maximizing" notion applicable to discrete-trial probability learning experiments: It holds that animals will choose an alternative with the greater probability of reinforcement at a given moment. The rats' behavior on the majority lever in this experiment can be accounted for, in part, by assuming a momentary maximizing strategy.

The behavior on the minority lever, in contrast to that on the majority one, is more difficult to explain. Group ALT showed more lose-shift than win-shift behavior, whereas Group REP showed more win-shift than lose- shift behavior (Tables 3a and 3b). The momentary maximizing notion seems to predict exactly the reverse pattern of results. Why this pattern should occur is not clear. The minority-lever response strategies observed did not, however, contribute much to the overall choice behavior, since few responses were made on that lever. Such responses as were made on the minority lever for ALT and REP subjects appear to be produced mainly by winshift and lose-shift responses for Groups ALT and REP, respectively, on the majority lever. And since these two groups earned more food than did Group RAN, it seems that subjects trained with sequential dependencies different from .5 as a whole momentarily maximized.

ALT and REP subjects, however, do not seem to have followed the momentary maximizing rule exclusively. After a majority response, lose-stays for Group ALT and 
Table 3b

Distribution of Obtained Reinforcers Immediately Following Different Outcomes During the Last Six Sessions

\begin{tabular}{|c|c|c|c|c|c|c|c|c|c|}
\hline \multirow[b]{2}{*}{ Group } & \multirow[b]{2}{*}{ Rat } & \multicolumn{2}{|c|}{$\begin{array}{c}\text { Following } A_{1} \\
\text { Reinforced } \\
\end{array}$} & \multicolumn{2}{|c|}{$\begin{array}{l}\text { Following } A_{1} \\
\text { Unreinforced }\end{array}$} & \multicolumn{2}{|c|}{$\begin{array}{c}\text { Following } \mathrm{A}_{2} \\
\text { Reinforced }\end{array}$} & \multicolumn{2}{|c|}{$\begin{array}{l}\text { Following } \mathbf{A}_{2} \\
\text { Unreinforced }\end{array}$} \\
\hline & & $E_{1}$ & $E_{2}$ & $E_{1}$ & $E_{2}$ & $E_{1}$ & $\mathrm{E}_{2}$ & $E_{1}$ & $E_{2}$ \\
\hline RAN & $\begin{array}{r}1 \\
6 \\
7 \\
11 \\
15 \\
17 \\
19 \\
23 \\
26\end{array}$ & $\begin{array}{l}61 \\
62 \\
62 \\
49 \\
59 \\
64 \\
61 \\
64 \\
64\end{array}$ & $\begin{array}{l}1 \\
0 \\
1 \\
2 \\
0 \\
0 \\
2 \\
0 \\
0\end{array}$ & $\begin{array}{l}44 \\
44 \\
44 \\
33 \\
45 \\
45 \\
41 \\
45 \\
45\end{array}$ & $\begin{array}{l}1 \\
0 \\
0 \\
3 \\
0 \\
0 \\
1 \\
0 \\
0\end{array}$ & $\begin{array}{l}1 \\
0 \\
1 \\
2 \\
0 \\
0 \\
2 \\
0 \\
0\end{array}$ & $\begin{array}{l}0 \\
0 \\
0 \\
0 \\
0 \\
0 \\
0 \\
0 \\
0\end{array}$ & $\begin{array}{l}2 \\
1 \\
1 \\
9 \\
0 \\
0 \\
2 \\
0 \\
0\end{array}$ & $\begin{array}{l}0 \\
0 \\
0 \\
0 \\
0 \\
0 \\
0 \\
0 \\
0\end{array}$ \\
\hline $\begin{array}{l}\text { Total } \\
\mathrm{E}_{1} \text { Percent }\end{array}$ & & \multicolumn{2}{|c|}{98.9} & \multicolumn{2}{|c|}{98.7} & \multicolumn{2}{|c|}{100.0} & 15 & 100.0 \\
\hline ALT & $\begin{array}{r}2 \\
4 \\
9 \\
10 \\
13 \\
16 \\
21 \\
24 \\
26\end{array}$ & $\begin{array}{l}38 \\
22 \\
34 \\
33 \\
25 \\
24 \\
23 \\
34 \\
22\end{array}$ & $\begin{array}{r}0 \\
21 \\
11 \\
4 \\
17 \\
10 \\
16 \\
7 \\
10\end{array}$ & $\begin{array}{l}72 \\
48 \\
59 \\
66 \\
52 \\
49 \\
48 \\
59 \\
54\end{array}$ & $\begin{array}{l}0 \\
0 \\
0 \\
0 \\
0 \\
0 \\
0 \\
0 \\
0\end{array}$ & $\begin{array}{r}0 \\
13 \\
8 \\
4 \\
15 \\
11 \\
14 \\
8 \\
8\end{array}$ & $\begin{array}{l}0 \\
0 \\
0 \\
0 \\
0 \\
0 \\
0 \\
0 \\
0\end{array}$ & $\begin{array}{l}0 \\
7 \\
2 \\
1 \\
4 \\
8 \\
6 \\
1 \\
8\end{array}$ & $\begin{array}{l}0 \\
0 \\
0 \\
0 \\
1 \\
2 \\
2 \\
1 \\
0\end{array}$ \\
\hline $\begin{array}{l}\text { Total } \\
E_{1} \text { Percent }\end{array}$ & & \multicolumn{2}{|c|}{72.6} & \multicolumn{2}{|c|}{100.0} & \multicolumn{2}{|c|}{100.0} & 37 & 6 \\
\hline REP & $\begin{array}{r}3 \\
5 \\
8 \\
12 \\
14 \\
18 \\
20 \\
22 \\
27\end{array}$ & $\begin{array}{l}79 \\
75 \\
63 \\
86 \\
68 \\
73 \\
71 \\
66 \\
86\end{array}$ & $\begin{array}{l}0 \\
0 \\
0 \\
0 \\
0 \\
4 \\
2 \\
1 \\
0\end{array}$ & $\begin{array}{r}9 \\
11 \\
5 \\
11 \\
1 \\
5 \\
4 \\
5 \\
12\end{array}$ & $\begin{array}{r}14 \\
15 \\
26 \\
12 \\
24 \\
18 \\
16 \\
17 \\
8\end{array}$ & $\begin{array}{l}3 \\
3 \\
8 \\
4 \\
8 \\
5 \\
3 \\
9 \\
3\end{array}$ & $\begin{array}{l}0 \\
1 \\
2 \\
1 \\
0 \\
3 \\
1 \\
1 \\
0\end{array}$ & $\begin{array}{r}8 \\
7 \\
11 \\
3 \\
12 \\
8 \\
10 \\
9 \\
3\end{array}$ & $\begin{array}{l}0 \\
1 \\
1 \\
1 \\
0 \\
0 \\
0 \\
2 \\
0\end{array}$ \\
\hline $\begin{array}{l}\text { Total } \\
\mathrm{E}_{1} \text { Percent }\end{array}$ & & 667 & 7 & 63 & 150 & 46 & 9 & 71 & 5 \\
\hline
\end{tabular}

Note $-A_{1}=$ the response to the majority lever; $A_{2}=$ the response to the minority lever; $E_{1}=$ the reinforcer obtained on the majority lever; $E_{2}=$ the reinforcer obtained on the minority lever.

win-stays for Group REP were made almost perfectly (above $90 \%$ ), whereas the percentages of win-shifts and lose-shifts were much lower for Groups ALT and REP, respectively. Stay responses on the majority lever would be essentially congruent with the overall contingency that requires consistent responding to that lever. Of stay responses, win-stays for Group REP and lose-stays for Group ALT are both congruent with local as well as overall contingencies, which may thus have rendered these responses highly probable. Shift responses to the minority lever, on the other hand, can be congruent with a momentary maximizing rule but not with the overall contingency generally; that is, the two response rules, local and overall, would in this case sometimes compete with each other. This competition may have lowered the frequency of shift responses as compared with stays. Thus, the subjects' choice behavior might have been controlled by both molecular and molar structures of reinforcement. A simi- lar analysis applies to behavior on the minority lever. Shifts to the majority lever which are congruent with the overall contingency were less frequent than stays not congruent with it.

Silberberg and his colleagues (Silberberg \& Williams, 1974; Silberberg, Hamilton, Ziriax, \& Casey, 1978) have proposed a "momentary maximizing with errors model." This model hypothesizes that choice behavior is essentially controlled by a momentary maximizing rule, but that subjects can remember the loci of prior choices only for a short time. It has been well illustrated with pigeons that as ITI increases, the likelihood of optimal responding based on prior choices and/or outcomes decreases (Shimp, 1976; Silberberg \& Williams, 1974). A modification of this model could account for the present results. The ITI used in the present experiment, $15 \mathrm{sec}$, may have been too long for rats to remember reliably the loci of preceding choices and their outcomes. To the extent that the sub- 
jects forgot these features of prior events, choice behavior would be less likely to be controlled by the molecular contingencies, thus heightening the likelihood of control by a molar variable (e.g., overall contingency). A problem for this account is that Silberberg and Williams have reported that pigeons tended to momentarily maximize in terms of relative response rate with even longer ITIs than that used here ( 22 or $120 \mathrm{sec}$ ), although successive choices were statistically independent with these ITIs. The contradiction between the results of Silberberg and Williams and those of the present study could be due to the different experimental procedures used: The former study employed a schedule similar to a trial-based concurrent VIVI, where a response to a given alternative produces some increment of reinforcement probability for the first response to another alternative; the present experiment used a traditional probability learning procedure with noncorrection. The occurrence of nearly exhaustive responding to the majority lever in Group RAN indicates that the overall contingency had strong control of choice behavior. This would have prevented the subjects from following the momentary maximizing strategy exclusively.

Analyses of distributions of responses and reinforcements following different outcomes failed to find a close correspondence between the relative frequencies of majority responses and those of reinforcements on the majority lever. These results seem to provide little evidence for a matching relation following a given outcome.

To evaluate molar and molecular accounts of matching behavior on concurrent VI-VI schedules, several discrete-trial experiments (Nevin, 1969; Shimp, 1966; Silberberg et al., 1978) have examined whether pigeons show a tendency toward momentary maximizing despite showing overall matching. It has been suggested, however, that a finding of momentary maximizing within overall matching would not necessarily be inconsistent with a molar account of matching (Herrnstein \& Loveland, 1975; Nevin, 1979) and that these studies cannot play a critical role in determining the relative importance of molar and molecular analyses. Silberberg and Williams (1974), in contrast, employed a procedure in which the relative response rate was affected by the extent to which animals momentarily maximize. In their study, if matching occurred, the relative response rate would equal .57 . If, however, an exact momentary maximizing strategy was adopted, the appropriate response pattern would be single alternation between alternatives, leading to a relative response rate of .50 , a value that deviates from matching. Silberberg and Williams found that the birds responded approximately equally on the two keys, despite the unequal reinforcement frequencies that such responding produced. The present study is in line with theirs in that the effect of a local response rule was manifested in the overall choice measure as well as in the molecular response structure. The results of the present experiment showed that rats' choice behavior was governed by local as well as overall reinforcement contingencies. Indeed, a molar analysis (Herrnstein, 1970) cannot explain why the subjects in Groups ALT and REP showed lower frequencies of choosing the majority lever than Group RAN, despite equal overall reinforcement probabilities for the three groups: If animals had not been controlled by the molecular contingencies, all three groups would have shown exclusive responding to the majority lever. A molecular analysis therefore seems appropriate.

\section{REFERENCES}

DE VILLIERS, P. (1977). Choice in concurrent schedules and a quantitative formulation of the law of effect. In W. K. Honig \& J. E. R. Staddon (Eds.), Handbook of operant behavior. Englewood Cliffs, NJ: Prentice-Hall.

Hale, J. M., \& Shimp, C. P. (1975). Molecular contingencies: Reinforcement probability. Journal of the Experimental Analysis of Behavior, 24, 315-321.

Herrnstein, R. J. (1970). On the law of effect. Journal of the Experimental Analysis of Behavior, 13, 243-266.

HeRRNSTEIN, R. J., \& Loveland, D. H. (1975). Maximizing and matching on concurrent ratio schedules. Journal of the Experimental Analysis of Behavior, 24, 107-116.

LEHR, R., \& PAVLIK, W. B. (1970). Within-subjects procedural variations in two-choice probability learning. Psychological Reports, 26, 651-657.

Mackintosh, N. J. (1974). The psychology of animal learning. London: Academic Press.

MEYER, D. R. (1960). The effects of differential probabilities of reinforcement on discrimination learning by monkeys. Journal of Comparative and Physiological Psychology, 53, 173-175.

NEVIN, J. A. (1969). Interval reinforcement of choice behavior in discrete trials. Journal of the Experimental Analysis of Behavior, 12, 875-885

NEVIN, J. A. (1979). Overall matching versus momentary maximizing: Nevin (1969) revisited. Journal of Experimental Psychology: Animal Behavior Processes, 5, 300-306.

Poland, S. F., \& WarRen, J. M. (1967). Spatial probability learning by cats. Psychonomic Science, 8, 487-488.

Shimp, C. P. (1966). Probabilistically reinforced choice behavior in pigeons. Journal of the Experimental Analysis of Behavior, 9, 443-455.

ShImP, C. P. (1969). Optimal behavior in free-operant experiments. Psychological Review, 76, 97-112.

SHIMP, C. P. (1975). Perspectives on the behavioral unit: Choice behavior in animals. In W. K. Estes (Ed.), Handbook of learning and cognitive processes (Vol. 2). Hillsdale: NJ: Erlbaum.

SHIMP, C. P. (1976). Short-term memory in the pigeon: The previously reinforced response. Journal of the Experimental Analysis of Behavior, 26, $487-493$.

Silberberg, A., Hamilton, B., Ziriax, J. M., \& Casey, J. (1978). The structure of choice. Journal of Experimental Psychology: Animal Behavior Processes, 4, 368-398.

Silberberg, A., \& Williams, D. R. (1974). Choice behavior on discrete trials: A demonstration of the occurrence of a response strategy. Journal of the Experimental Analysis of Behavior, 21, 315-322.

Staddon, J. E. R., Hinson, J. M., \& KRAM, R. (1981). Optimal choice. Journal of the Experimental Analysis of Behavior, 35, 397-412.

Sutherland, N. S., \& MaCKINTOSH, N. J. (1971). Mechanisms of animal discrimination learning. New York: Academic Press.

UHL, C. N. (1963). Two-choice probability learning in the rat as a function of incentive, probability of reinforcement, and training procedure. Journal of Experimental Psychology, 66, 443-449.

Williams, B. A. (1972). Probability learning as a function of momentary reinforcement probability. Journal of the Experimental Analysis of Behavior, 17, 363-368.

(Manuscript received September 9, 1983; revision accepted for publication November $5,1984$. ) 